\title{
SPACE SHUTTLE COLUMBIA POST-ACCIDENT ANALYSIS AND INVESTIGATION
}

\author{
Steve McDanels \\ NASA \\ TA-H1 Kennedy Space Center, FL, 32899 USA \\ steve.mcdanels@nasa.gov
}

\section{Summary}

Although the loss of the Space Shuttle Columbia and its crew was tragic, the circumstances offered a unique opportunity to examine a multitude of components which had experienced one of the harshest environments ever encountered by engineered materials: a break up at a velocity in excess of Mach 18 and an altitude exceeding 200,000 feet $(63 \mathrm{KM})$, resulting in a debris field 645 miles $/ 1,038 \mathrm{KM}$ long and 10 miles/16 KM wide. Various analytical tools were employed to ascertain the sequence of events leading to the disintegration of the Orbiter and to characterize the features of the debris. The testing and analyses all indicated that a breach in a left wing reinforced carbon/carbon composite leading edge panel was the access point for hot gasses generated during re-entry to penetrate the structure of the vehicle and compromise the integrity of the materials and components in that area of the Shuttle.

The analytical and elemental testing utilized such techniques as X-Ray Diffraction (XRD), Energy Dispersive X-Ray (EDX) dot mapping, Electron Micro Probe Analysis (EMPA), and X-Ray Photoelectron Spectroscopy (XPS) to characterize the deposition of intermetallics adjacent to the suspected location of the plasma breach in the leading edge of the left wing, Fig.1.

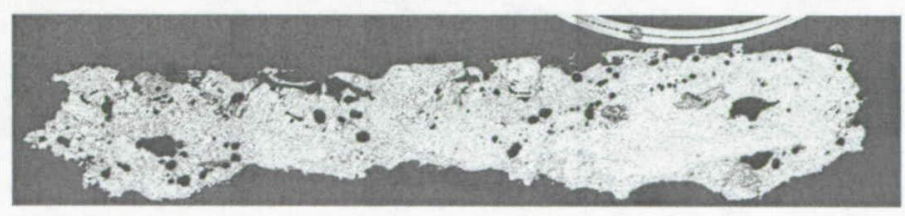

FIGURE 1. Micrograph of a Left Wing Carrier Panel Slag Deposit. Cummings [1]

Fractographic and metallographic analyses of several pieces of debris, Fig. 2, were performed to characterize such fracture characteristics as broomstrawing and feathering of aluminum alloys; suspected stress-assisted grain boundary oxidation (SAGBO) of Inconel components; and intergranular high temperature fracture features observed on several A286 stainless steel spar fittings. 


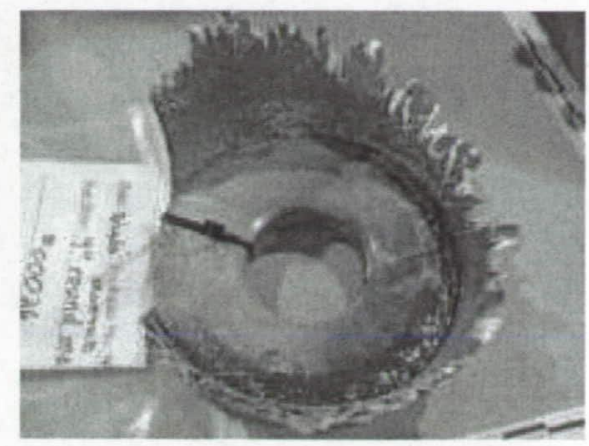

FIGURE 2. Interior view of aluminum drag chute canister. Parker [2]

The examination of the debris' fracture surfaces, and of metallographically-prepared specimens harvested from the debris, was performed via scanning electron microscope. The resultant features and characteristics were compared to those of laboratory exemplars of similar base materials. The observed featrues, along with the results from the elemental analytical testing, helped the Space Shuttle Columbia accident investigation team reconstruct the mishap and help determine the sequence of events which ultimately led to the loss of the vehicle.

The debris from the Columbia accident now resides in the Vehicle Assembly Building (VAB) at the Kennedy Space Center. Some of the debris is on display, while the majority is in storage in the $\mathrm{VAB}$. A process is in place whereby universities and professional societies can request pieces of debris for educational and research purposes, Fig.3.

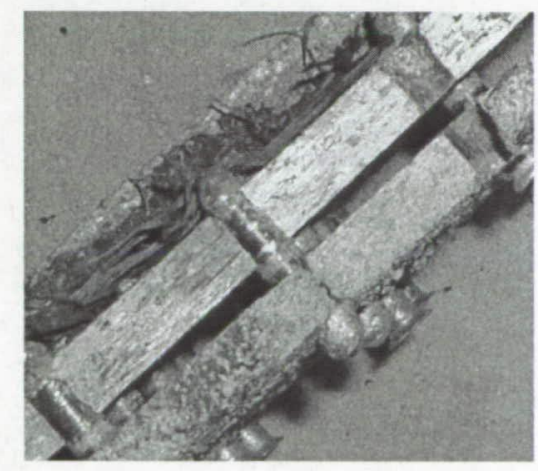

FIGURE 3. Debris sample loaned out for educational purposes. NASA [3]

\section{References}

1. Cummings, V. J., XPS, Metallographic and SEM X-Ray elemental Dot Map Analysis of STS-107 Debris Sample 24543-1, National Aeronautics and Space Administration, KSC-MSL-2003-149, 2003.

2. Parker, D. S., Optical and SEM/EDS Analysis of STS-107 Debris Sample 58693-1, National Aeronautics and Space Administration, KSC-MSL-2003-208, 2003.

3. National Aeronautics and Space Administration, Columbia Debris Loan Request CRP-28, 2005. 